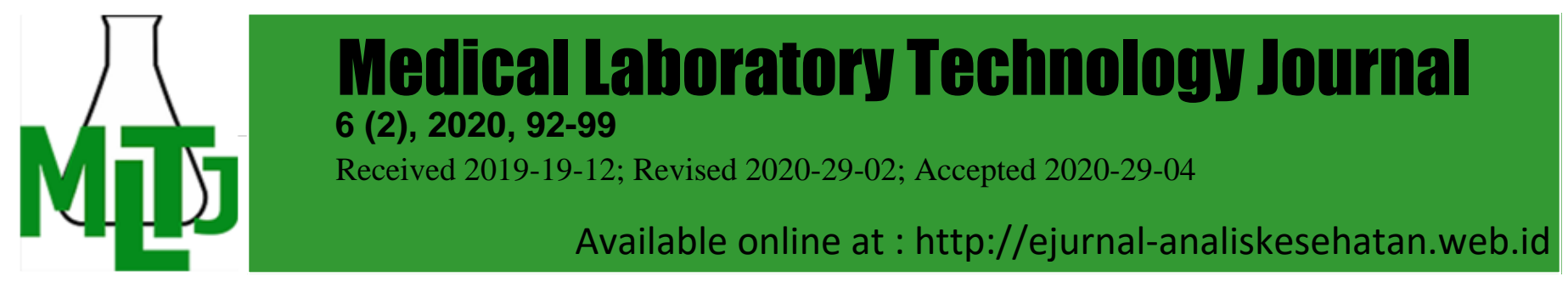

\title{
Early Relapse After Autologous Stem Cell Transplantation in Multiple Myeloma is Still Prognostic in the Era of Novel Agents
}

\author{
Semih Başcı ${ }^{1 *}$, Tuğçe Nur Yiğenoğlu1 ${ }^{1}$ Bahar Uncu Ulu ${ }^{1}$, Mehmet Bakırtaş ${ }^{1}$, \\ Derya Şahin'1, Tahir Darçın¹, Jale Yıldız', Alparslan Merdin'1, Nuran Ahu Baysal', \\ Dicle İskender ${ }^{1}$, Merih Kızıl Çakar ${ }^{1}$, Mehmet Sinan Dal ${ }^{1}$, Tuba Hacıbekiroğlu², \\ Fevzi Altuntaş ${ }^{1}$
}

${ }^{1}$ Department of Hematology and Bone Marrow Transplantation Center, Ankara Dr. Abdurrahman Yurtaslan Oncology Training and Research Hospital, University of Health Sciences, Ankara, Turkey. ${ }^{2}$ Department of Hematology, Sakarya University Hospital, Medical Faculty, Sakarya, Turkey. *E-mail: dr.semihbasci@gmail.com

DOI: $10.31964 / \mathrm{mltj} . v 0 i 0.281$

\begin{abstract}
Significant improvements in the prognosis of Multiple Myeloma (MM) have recently observed in the era of novel agents. Induction treatment, including new agents followed by conditioning regimen and upfront autologous stem cell transplantation (ASCT), has been accepted as the standard treatment approach for newly diagnosed eligible MM patients. Despite novel agents, upfront ASCT is still superior to conventional chemotherapy alone. Previous studies revealed that the duration between ASCT and relapse had predicted overall survival (OS), and meantime, it was widely used to determine the potential benefit from a second ASCT. However, the majority of the data collected reflects the treatment modalities before novel agents. In this study, we aimed to investigate the impact of post-transplantation early relapse (ER) on survival in the era of novel agents. The results of $155 \mathrm{MM}$ patients that underwent ASCT at our center between January 2010 and May 2018 were analyzed retrospectively. The median follow-up duration was 20 months in the ER group, 27 months in the non-ER group, and 24 months in all patients. 33.3\% of patients in the ER group and $71.4 \%$ of patients in the non-ER group were alive at the time of analysis. Median OS was $17(95 \% \mathrm{Cl}, 12,8-21,2)$ months in the ER group and 33 (95\% Cl,18,9$47,1)$ months in the non-ER group. We found a statistically significant relationship between the ER and the poor OS $(\mathrm{p}:<0.001)$. Our study reveals that in the era of novel agents, ER still related to poor survival. Therefore, comprehensive studies needed to develop new strategies for early relapsed patients.
\end{abstract}

Keyword: Multiple myeloma; autologous stem cell transplantation; early relapse

\section{INTRODUCTION}

Multiple myeloma (MM) is a plasma cell malignancy in which clonal plasma cells produce a monoclonal immunoglobulin. MM is the second most common hematologic malignancy. Median age at diagnosis is 70 years, and two-thirds of the patients are older than 65 years (Palumbo A., 2012 and Harousseau J.L., 2008). The advent of immunomodulatory drugs and proteasome inhibitors started a new era in the therapy of MM (Szalat R., 2019). Patients treated with these new agents have improved overall survival (OS) compared with patients who have never exposed to these agents (Kumar S.K., 2008). In the last five years, the Food and Drug Administration approved pomalidomide, carfilzomib, ixazomib, panobinostat, and two monoclonal antibodies

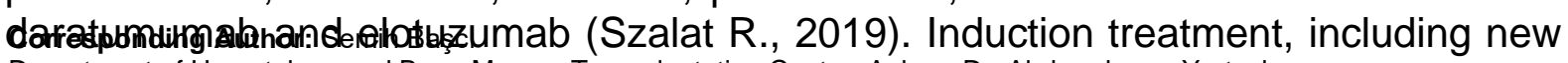
Department of Hematology and Bone Marrow Transplantation Center, Ankara Dr. Abdurrahman Yurtaslan Oncology Training and Research Hospital, University of Health Sciences. 06200 Yenimahalle, Ankara, Turkey. Email: dr.semihbasci@gmail.com 
agents followed by conditioning regimen and upfront autologous stem cell transplantation (ASCT), has accepted as the standard treatment approach for newly diagnosed fit MM patients. Even in the era of novel agents upfront, ASCT is still superior to conventional chemotherapy alone (Mikhael J., 2019). Recently, the benefit of high-dose chemotherapy followed by ASCT has verified in the treatment approaches, including immunomodulatory drugs and proteasome inhibitors (Palumbo A., 2014; Gay F., 2015; Attal M., 2017; Gay F., 2017).

However, even with novel agents, some patients develop resistance over time and continue to experience recurrent relapses; therefore, long-term disease control cannot achieve (Martinelli G., 2000; Corradini P., 2003). The prognosis of MM patients is quite heterogeneous. Therefore, it is very crucial to find out every prognostic factor to predict survival, and for patients who expected to have shorter OS, new treatment strategies should consider. Factors about the host and disease itself, such as the properties of the tumor, the microenvironment, age, and comorbidities, were shown to be the significant prognostic features (Kumar S.K., 2008; Brenner H., 2008; Kastritis E., 2009). The time until relapse seems to be an important prognostic factor, and early relapse (ER) could be indicating high-risk disease biology (Jimenez-Zepeda V.H., 2015; Majithia N., 2016; Palumbo A., 2007). The previous studies revealed that duration between ASCT and relapse had predicted the OS, and meantime it was widely used to determine the potential benefit from a second ASCT (Jimenez-Zepeda V.H., 2015; Kumar S., 2008; Michaelis L.C., 2013). However, the majority of the data collected reflects the treatment modalities before the novel agents, and the developments in the past decade, including the novel agents and improvements in the patient care of pre and post-transplantation period, should make it very likely that these predictions will change. In this study, we aimed to investigate the effects of posttransplantation ER on survival in the era of new agents.

\section{MATERIALS AND METHOD}

The results of $155 \mathrm{MM}$ patients that underwent ASCT at Dr.Abdurrahman Yurtaslan Ankara Oncology Training and Research Hospital between January 2010 and May 2018 were analyzed retrospectively. The ethics committee approved the study of our center (2019-09/399). The patients' age, gender, myeloma subgroup, stages, number of chemotherapy lines and radiotherapy $(\mathrm{RT})$ they received before ASCT, presence of renal failure, the dose of melphalan they received, quantity of infused $\mathrm{CD} 34^{+}$cell and the pre-ASCT response given in Table 1.

The patients that did not receive bortezomib in the induction regimen not included in the study. Tandem transplantation patients described as having the second ASCT within six months without any progression or relapse after the first ASCT not included in the study. The patients that underwent ASCT 12 months after diagnosis that have follow-up durations less than 100 days or die within the first 100 days postASCT not included in the study. The most frequently used induction treatment consisted of bortezomib, cyclophosphamide, and dexamethasone. Elderly patients with comorbidities received bortezomib and dexamethasone regimen. The patients' stages at the time of diagnosis recorded with International Staging System (ISS), Revised International Staging System (R-ISS), Durie-Salmon Stages (DS), and treatment response evaluated according to the criteria of International Myeloma Working Group (Durie BG,2006).

Table 1: Patients' characteristics 


\begin{tabular}{|c|c|}
\hline & Patient Population (n) \\
\hline \multirow{2}{*}{$\begin{array}{l}\text { Age (median) } \\
\text { Gender }\end{array}$} & $56(25-81)$ \\
\hline & Females $(n): 57 /$ Males $(n): 98$ \\
\hline \multirow{4}{*}{$\begin{array}{l}\text { MM } \\
\text { Subgroup }\end{array}$} & Heavy Chain $(n): 116$ \\
\hline & Light Chain (n): 32 \\
\hline & Non-secretory $(n): 3$ \\
\hline & Not evaluated $(n): 4$ \\
\hline \multirow{4}{*}{ ISS } & ISS I(n): 40 \\
\hline & ISS II(n): 49 \\
\hline & ISS III(n): 41 \\
\hline & Not evaluated $(n): 25$ \\
\hline \multirow{4}{*}{ R-ISS } & R-ISS I (n): 21 \\
\hline & R-ISS II (n): 60 \\
\hline & R-ISS III $(n): 11$ \\
\hline & Not evaluated $(n): 63$ \\
\hline \multirow{4}{*}{ Durie Salmon } & DS1(n): 5 \\
\hline & DS2(n):16 \\
\hline & DS3(n):129 \\
\hline & Not evaluated $(n): 5$ \\
\hline \multirow{6}{*}{$\begin{array}{l}\text { Pre-transplantation } \\
\text { response }\end{array}$} & $\mathrm{CR}(\mathrm{n}): \quad 58$ \\
\hline & $\operatorname{VGPR}(n): 39$ \\
\hline & $\operatorname{PR}(n): \quad 41$ \\
\hline & Stable(n): 10 \\
\hline & Refractory $(n): 3$ \\
\hline & Not evaluated $(n): 4$ \\
\hline \multirow{5}{*}{$\begin{array}{l}\text { Chemotherapy } \\
\text { line(s) }\end{array}$} & 1 line $(n): 50$ \\
\hline & 2 lines $(n): 90$ \\
\hline & 3 lines $(n): 9$ \\
\hline & 4 line $(n): 2$ \\
\hline & Not evaluated $(n): 4$ \\
\hline \multirow{2}{*}{ Melphalan dose } & $140 \mathrm{mg} / \mathrm{m}^{2}(\mathrm{n}): 14$ \\
\hline & $200 \mathrm{mg} / \mathrm{m}^{2}(\mathrm{n}): 141$ \\
\hline \multirow{2}{*}{$\begin{array}{l}\text { Renal failure } \\
\text { (GFR }<50 \mathrm{ml} / \mathrm{min})\end{array}$} & Present(n): 7 \\
\hline & None(n): 148 \\
\hline \multirow{2}{*}{ Radiotherapy } & Applied(n): 21 \\
\hline & Not-applied(n):134 \\
\hline $\begin{array}{l}\text { Infused CD34+ cell } \\
\text { (median) }\end{array}$ & $4.62 \times 10^{6} / \mathrm{kg}(2.4-13.4)$ \\
\hline
\end{tabular}

ISS: International staging system, R-ISS: revised-international staging system, CR: complete response, VGPR: very good partial response, PR: partial response, GFR: glomerular filtration rate. 
109 patients among 155 patients mobilized with a total of $10 \mu \mathrm{g} / \mathrm{kg}$ subcutaneous granulocyte stimulating agent (G-CSF) in 2 divided doses $(2 \times 5 \mu \mathrm{g} / \mathrm{kg})$. Sixteen patients had mobilization failure with G-CSF alone, and they mobilized with high-dose cyclophosphamide $\left(4.000 \mathrm{mg} / \mathrm{m}^{2}\right)$ and G-CSF combination. Three patients had mobilization failure with G-CSF alone and high-dose cyclophosphamide (4.000 $\mathrm{mg} / \mathrm{m}^{2}$ ) G-CSF combination, and they mobilized with plerixafor and G-CSF combination. Mobilization data of 27 patients could not reach from the records. While the patients $\geq 70$ years or who have a serum creatinine level of $\geq 2 \mathrm{mg} / \mathrm{dL}$ received 140 $\mathrm{mg} / \mathrm{m}^{2}$ melphalan as the conditioning regimen, the remaining patients received 200 $\mathrm{mg} / \mathrm{m}^{2}$ melphalan. OS described the duration from the date of transplantation to the date of death or the latest follow-up date for the survivors. Progression-free survival (PFS) defined as the duration from the date of transplantation to the progress in disease, death, or date of latest follow-up for the progression-free patients. Transplantrelated mortality (TRM) was defined as the cumulative death within the first 100 days after allo-SCT without any evidence of disease progression. The engraftment definition for neutrophil defined as the first day when the absolute neutrophil count (ANC) was $>500 / \mathrm{mm}^{3}$ or $1000 / \mathrm{mm}^{3}$ for three consecutive days without any support, and for thrombocytes it was defined as the first day when thrombocyte count was $>20000 / \mathrm{mm}^{3}$ for three consecutive days without any support (Rihn C, 2004).

According to international uniform response criteria for multiple myeloma, ER defined as relapse within one year after the date of ASCT or progressive disease (Durie BG,2006). Patients divided into two groups: the patients with relapse within the first 12 months of post-ASCT and the patients with relapse after 12 months or the patients with no relapse until the latest follow-up. The relationships between $\mathrm{OS}$ and age, gender, MM subtype (heavy chain, light chain, nonsecretory), International Staging System (ISS), Revised International Staging System (R-ISS), Durie Salmon stages (DS), pre-ASCT chemotherapy, melphalan dose, response to the induction treatment, the duration between diagnosis and ASCT and the duration to the progression investigated.

\section{Statistical Methods}

IBM SPSS Statistics (version 21) software used for statistical analysis. Descriptive statistics used to summarize the data. Categorical data expressed as a ratio and numerical data were expressed as median and mean \pm standard deviation. Kaplan-Meier Survival analysis test used to evaluate overall survival and progressionfree survival. Factors influencing OS and PFS among the groups were analyzed employing a log-rank test. $\mathrm{P}<0.05$ value was set as statistically significant.

\section{RESULTS AND DISCUSSION}

155 patients that underwent ASCT within 12 months after diagnosis and received bortezomib in induction treatment included in the study and the data analyzed retrospectively. 27 (17.4\%) patients had ER after ASCT, 128 (82.6\%) patients had a late relapse (after 12 months) or observed in remission. The median follow-up duration was 20 months in the ER group, 27 months in the non-ER group, and 24 months in all patients. 33.3\% of patients in the ER group and $71.4 \%$ of patients in the non-ER group were alive at the time of analysis. Median OS was $17(95 \% \mathrm{Cl}, 12,8-21,2)$ months in the ER group and $33(95 \% \mathrm{Cl}, 18,9-47,1)$ months in the non-ER group. We observed a statistically significant relationship between the ER and the poor OS $(p:<0.001)$.

We did not find any statistically significant relationship between OS and gender, MM subtype, ISS, Durie Salmon stage, number of chemotherapy lines received, 
melphalan dose, pre-ASCT response, and the duration between progression and ASCT. There was only a relationship between R-ISS and OS $(p=0.033)$.

Post-ASCT CR rate in ER group was $77.8 \%, 62.5 \%$ in the non-ER group; while VGPR rate was 3.7\% in ER group, $10.2 \%$ in the non-ER group; PR rate was $3.7 \%$ in the ER group, $18.8 \%$ in the non-ER group; there was no statistically significant difference among the groups regarding the post-ASCT responses ( $p: 0.095)$.

Table 2: The Factors Impacting OS

\begin{tabular}{lll}
\hline & PFS & OS \\
\hline Gender & 0.873 & 0.775 \\
MM subtype & 0.229 & 0.215 \\
ISS & 0.522 & 0.560 \\
R-ISS & 0.339 & $0.033^{*}$ \\
Durie Salmon stage & 0.824 & 0.973 \\
Chemotherapy line(s) received & 0.252 & 0.707 \\
Melphalan dose & 0.607 & 0.795 \\
Pre-transplantation response & 0.066 & 0.846 \\
\hline
\end{tabular}

PFS: progression-free survival, OS: overall survival, ISS: international staging system,

R-ISS: revised-international staging system

The duration between ASCT and relapse seems to be an important prognostic factor, and ER could be indicating high-risk disease biology (Jimenez-Zepeda V.H., 2015; Majithia N., 2016; Palumbo A., 2007). Developments in the past decade, including the novel agents and improvements in the patient care of the pre and posttransplantation period, may overcome the adverse impact of ER on prognosis. However, the majority of the data collected reflects the treatment modalities before the novel agents. The significance of ER on survival was first described by Kumar et al. in 2008. Among 494 patients that treated with conventional therapy and ASCT, $24 \%$ had $E R$, and in the non-ER group, OS was 41.8 months; it was 10.8 months in the ER group (Kumar S., 2008). In a retrospective study, Venner et al. found out that exposure to new agents after relapse improved the survival of ER patients (Venner C.P., 2011).

In the study conducted by Lee et al., including 257 patients that underwent novel agent-based treatment and ASCT, $13.6 \%$ of the patients had ER. While the median OS in the ER group was 17.8 months, the median OS in the non-ER group could not reach throughout the follow-up duration $(p=0.0001)$ (Lee $H ., 2018)$. In the study conducted with 432 patients that underwent ASCT at Mayo Clinic, 94 (22\%) of the patients had a relapse within 12 months after ASCT. While the median OS had been 23.9 months in the ER group, it was 82.2 months in the non-ER group. Among the 265 patients with relapse after the transplantation, the median OS was 7.8 months in the ER group and 39.6 months in the late relapse group (Kumar S., 2008). In the study conducted by Ong et al. with 215 patients that underwent ASCT, they reported that the risk of ER decreased with the new agents compared to the conventional treatment ( $p=0.234)$ (Ong S.Y., 2016). In our study, while $27(17.4 \%)$ patients had a relapse within the first 12 months of ASCT, $128(82.6 \%)$ patients had a late relapse (after 12 months), or they observed in remission (non-ER group). The median survival was $17(95 \% \mathrm{Cl}, 12,8-21,2)$ months in the ER group and 33 (95\% $\mathrm{Cl}, 18,9-47,1)$ months in the non-ER group. We found a statistically significant relationship between the ER group and the non-ER group concerning OS $(p:<0.001)$. 
So, our study suggests that even in the era of new agents, ER is still a poor prognostic factor for OS.

In the study conducted by Lee et al., $\geq$ VGPR response rate was $51.4 \%$ in the ER group and $80.5 \%$ in the non-ER group ( $\mathrm{p}: 0.001)$. The total response rate was $35.6 \%$ in the ER group and $25.7 \%$ in the non-ER group (p: 0.003) (Lee H., 2018). In our study, the CR rate was $77.8 \%$ in ER group, $62.5 \%$ in non-ER group, VGPR rate was $3.7 \%$ in ER group, it was $10.2 \%$ in the non-ER group; PR rate was $3.7 \%$ in ER group, it was $18.8 \%$ in the non-ER group; we did not observe any statistically significant difference between 2 groups regarding post ASCT responses(p: 0.095). This suggests that ER is predictive for poor OS irrespective of post-transplant response. There were some limitations to this study. This was a retrospective analysis, and there was no information about complications of treatment. The superior side is that all of the patients in this study received at least one novel agent in the induction therapy.

\section{CONCLUSION}

The studies in both conventional chemotherapy and novel agent's era emphasize the significance of ER in MM patients. In the era of novel agents, the ER still related to poor survival. This supports that there is a group of patients with whom long term response could not maintain and whose prognoses continue to remain weak despite the improved results obtained with the inclusion of new treatments. Therefore, substantial studies should be done to develop new strategies for early relapsed patients.

\section{ACKNOWLEDGMENT}

None declared.

\section{CONFLICT OF INTEREST}

There were no conflicts of interest with related parties in this study.

\section{REFERENCE}

Attal, M., Lauwers-Cances, V., Hulin, C., Leleu, X., Caillot, D., Escoffre, M., Arnulf, B., Macro, M., Belhadj, K., Garderet, L., Roussel, M., Payen, C., Mathiot, C., Fermand, J. P., Meuleman, N., Rollet, S., Maglio, M. E., Zeytoonjian, A. A., Weller, E. A., Munshi, N., ... IFM 2009 Study (2017). Lenalidomide, Bortezomib, and Dexamethasone with Transplantation for Myeloma. The New England journal of medicine, 376(14), 1311-1320. https://doi.org/10.1056/NEJMoa1611750

Brenner, H., Gondos, A., \& Pulte, D. (2008). Recent major improvement in long-term survival of younger patients with multiple myeloma. Blood, 111(5), 2521-2526. https://doi.org/10.1182/blood-2007-08-104984

Corradini, P., Cavo, M., Lokhorst, H., Martinelli, G., Terragna, C., Majolino, I., ... Gahrton, G. (2003). Molecular remission after myeloablative allogeneic stem cell transplantation predicts a better relapse-free survival in patients with multiple myeloma. Blood, 102(5), 1927-1929. https://doi.org/10.1182/blood-2003-010189

Durie, B. G. M., Harousseau, J. L., Miguel, J. S., Bladé, J., Barlogie, B., Anderson, K., ... Morgan, G. (2006). International uniform response criteria for multiple myeloma. Leukemia, 20(9), 1467-1473. https://doi.org/10.1038/sj.leu.2404284 
Gay, F., Oliva, S., Petrucci, M. T., Conticello, C., Catalano, L., Corradini, P., ... Palumbo, A. (2015). Chemotherapy plus lenalidomide versus autologous transplantation, followed by lenalidomide plus prednisone versus lenalidomide maintenance, in patients with multiple myeloma: A randomised, multicentre, phase 3 trial. The Lancet Oncology, 16(16), 1617-1629. https://doi.org/10.1016/S1470-2045(15)00389-7

Gay, F., Oliva, S., Petrucci, M. T., Montefusco, V., Conticello, C., Musto, P., ... Boccadoro, M. (2017). Autologous transplant vs. oral chemotherapy and lenalidomide in newly diagnosed young myeloma patients: A pooled analysis. Leukemia, 31(8), 1727-1734. https://doi.org/10.1038/leu.2016.381

Harousseau, J.-L. (2008). Autologous transplantation for multiple myeloma. Annals of Oncology, 19, 128-133. https://doi.org/10.1093/annonc/mdn449

Jimenez-Zepeda, V. H., Reece, D. E., Trudel, S., Chen, C., Tiedemann, R., \& Kukreti, V. (2015). Early relapse after single auto-SCT for multiple myeloma is a major predictor of survival in the era of novel agents. Bone Marrow Transplantation, 50(2), 204-208. https://doi.org/10.1038/bmt.2014.237

Kastritis, E., Zervas, K., Symeonidis, A., Terpos, E., Delimbassi, S., Anagnostopoulos, N., ... Dimopoulos, M. A. (2009). Improved survival of patients with multiple myeloma after the introduction of novel agents and the applicability of the International Staging System (ISS): An analysis of the Greek Myeloma Study Group (GMSG). Leukemia, 23(6), 1152-1157. https://doi.org/10.1038/leu.2008.402

Kumar, S. K., Rajkumar, S. V., Dispenzieri, A., Lacy, M. Q., Hayman, S. R., Buadi, F. K., ... Gertz, M. A. (2008). Improved survival in multiple myeloma and the impact of novel therapies. Blood, 111(5), 2516-2520. https://doi.org/10.1182/blood2007-10-116129

Kumar, S., Mahmood, S. T., Lacy, M. Q., Dispenzieri, A., Hayman, S. R., Buadi, F. K., ... Gertz, M. A. (2008). Impact of early relapse after auto-SCT for multiple myeloma. Bone Marrow Transplantation, 42(6), 413-420. https://doi.org/10.1038/bmt.2008.180

Lee, H., Duggan, P., Chaudhry, A., Neri, P., Tay, J., Rashid-Kolvear, F., ... JimenezZepeda, V. H. (2018). Early Relapse for Multiple Myeloma Patients Undergoing Single Autologous Stem Cell Therapy: A Single-center Experience. Clinical Lymphoma, Myeloma, and Leukemia, 18(1), e69-e75. https://doi.org/10.1016/j.clml.2017.10.009

Martinelli, G., Terragna, C., Zamagni, E., Ronconi, S., Tosi, P., Lemoli, R. M., ... Cavo, M. (2000). Molecular remission after allogeneic or autologous transplantation of hematopoietic stem cells for multiple myeloma. Journal of Clinical Oncology, 18(11), 2273-2281. https://doi.org/10.1200/JCO.2000.18.11.2273

Majithia, N., Rajkumar, S. V., Lacy, M. Q., Buadi, F. K., Dispenzieri, A., Gertz, M. A., ... Kumar, S. K. (2016). Early relapse following initial therapy for multiple myeloma predicts poor outcomes in the era of novel agents. Leukemia, 30(11), 2208-2213. https://doi.org/10.1038/leu.2016.147

Michaelis, L. C., Saad, A., Zhong, X., Le-Rademacher, J., Freytes, C. O., Marks, D. I., ... Hari, P. (2013). Salvage Second Hematopoietic Cell Transplantation in Myeloma. Biology of Blood and Marrow Transplantation, 19(5), 760-766. https://doi.org/10.1016/j.bbmt.2013.01.004

Mikhael, J., Ismaila, N., Cheung, M. C., Costello, C., Dhodapkar, M. V., Kumar, S., ... Martin, T. (2019, May 10). Treatment of multiple myeloma: ASCO and CCO joint 
clinical practice guideline. Journal of Clinical Oncology, (37), pp. 1228-1263. https://doi.org/10.1200/JCO.18.02096

Ong, S. Y., De Mel, S., Chen, Y. X., Ooi, M. G., Surendran, S., Lin, A., ... Gopalakrishnan, S. K. (2016). Early relapse post autologous transplant is a stronger predictor of survival compared with pretreatment patient factors in the novel agent era: Analysis of the Singapore Multiple Myeloma Working Group. Bone Marrow Transplantation, 51(7), 933-937. https://doi.org/10.1038/bmt.2016.43

Palumbo, A., Cavallo, F., Gay, F., Di Raimondo, F., Yehuda, D. B., Petrucci, M. T., ... Cavo, M. (2014). Autologous transplantation and maintenance therapy in multiple myeloma. New England Journal of Medicine, 371(10), 895-905. https://doi.org/10.1056/NEJMoa1402888

Palumbo, A., Bringhen, S., Falco, P., Cavallo, F., Ambrosini, M. T., Avonto, I., ... Boccadoro, M. (2007). Time to first disease progression, but not $\beta 2$ microglobulin, predicts outcome in myeloma patients who receive thalidomide as salvage therapy. Cancer, 110(4), 824-829. https://doi.org/10.1002/cncr.22855

Palumbo, A., \& Cavallo, F. (2012, December 6). Have drug combinations supplanted stem cell transplantation in myeloma? Blood, (120), pp. 4692-4698. https://doi.org/10.1182/blood-2012-05-423202

Rihn, C., Cilley, J., Naik, P., Pedicano, A. V. J. \& Mehta, J. (2004). Definition of myeloid engraftment after allogeneic hematopoietic stem cell transplantation. Haematologica, 89(6), 763-764. Retrieved from http://www.ncbi.nlm.nih.gov/pubmed/15194552

Szalat, R., \& Munshi, N. C. (2019, January 1). Novel agents in multiple myeloma. Cancer Journal (United States), (25), pp. 45-53. https://doi.org/10.1097/PPO.0000000000000355

Venner, C. P., Connors, J. M., Sutherland, H. J., Shepherd, J. D., Hamata, L., Mourad, Y. A., ... Song, K. W. (2011). Novel agents improve survival of transplant patients with multiple myeloma, including those with high-risk disease defined by early relapse (<12 months). Leukemia and Lymphoma, 52(1), 34-41. https://doi.org/10.3109/10428194.2010.531409 